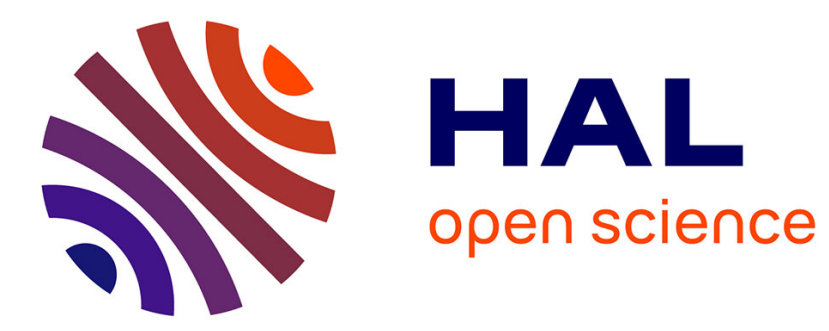

\title{
EFFECT OF REMNANT CRYSTALLINITY ON RESISTIVITY OF AMORPHOUS ALLOYS
}

\author{
A. Mogro-Campero, J. Walter
}

\section{To cite this version:}

A. Mogro-Campero, J. Walter. EFFECT OF REMNANT CRYSTALLINITY ON RESISTIVITY OF AMORPHOUS ALLOYS. Journal de Physique Colloques, 1980, 41 (C8), pp.C8-497-C8-500. 10.1051/jphyscol:19808124 . jpa-00220221

\section{HAL Id: jpa-00220221 https://hal.science/jpa-00220221}

Submitted on 1 Jan 1980

HAL is a multi-disciplinary open access archive for the deposit and dissemination of scientific research documents, whether they are published or not. The documents may come from teaching and research institutions in France or abroad, or from public or private research centers.
L'archive ouverte pluridisciplinaire HAL, est destinée au dépôt et à la diffusion de documents scientifiques de niveau recherche, publiés ou non, émanant des établissements d'enseignement et de recherche français ou étrangers, des laboratoires publics ou privés. 


\title{
EFFECT OF REMNANT CRYSTALLINITY ON RESISTIVITY OF AMORPHOUS ALLOYS
}

\author{
A. Mogro-Campero and J.L. Walter \\ General EZeetric Research \& Development Center, Schenectady, NY 12301, U.S.A.
}

\begin{abstract}
It is shown for the Co-B series that changes in the temperature coefficient of resistivity, $\alpha$, produced by a few percent of crystals within an amorphous matrix, are of the same order as changes of $\alpha$ with composition which have been reported in the literature, and interpreted in terms of physics of the amorphous state. Such low levels of crystalline fraction may escape notice by the standard methods of $x$-ray analysis or electron mieroscopy.
\end{abstract}

1. INTRODUCTION.- It is known that certain alloys can be made to be completely amorphous only over restricted composition ranges which are fixed partly by composition and partly by the method of preparation $/ 1 /$. The amorphous window is bounded by compositions which are highly crystalline as cast but the transition is not necessarily sharp. In this transition region, a small volume fraction of crystals may coexist with an amorphous matrix. The amount may be too small to be easily and unambiguously identified by existing techniques and, thus, may lead to incorrect analysis of measurements performed on supposedly amorphous alloys. The term "remnant" is meant to define this small and generally undesirable fraction. Similar effects can occur as a result of annealing an amorphous sample. The present study looks into the effect of remnant erystallinity on the electrical resistivity of amorphous Co-B metallic alloys. Both the resistivity and its temperature coefficient are significantly different in the amorphous and crystalline phases of an alloy, so that in a mixed phase system these parameters are a function of the remnant crystalline fraction. It is concluded that a few percent of erystals can cause changes in the temperature coefficient of resistivity which are of the order of changes which have been reported in the literature and interpreted in terms of physies of the amorphous state.

2. RESISTIVITY OF A MIXED PHASE SYSTEM.- The case of remnant crystallinity which is considered here can be described by a continuous amorphous phase of resistivity $\rho_{a}$ in which are embedded a volume fraction of crystals $f$ with resistivity $\rho_{c}$. The resistivity $\rho$ of such $a$ mixed phase system can be calculated and expressed in simple terms for the cases of isolated spheres /2 / (3Dthree dimensional case) and cyclindrical objects arranged in rectangular order /3/ (2D-two dimensional case). The results are

$$
\frac{\rho}{\rho_{\mathrm{Q}}}=\frac{2 R+1-f(1-R)}{2 R+1+2 f(1-R)}
$$

and

$$
\frac{\rho}{\rho_{g}}=\frac{R+1-f(1-R)}{R+1+f(1-R)}
$$

where $R=\rho_{c} / \rho_{a}$. The assumptions made in the derivation of these equations imply that they are valid for low values of $f$; however it has been shown that they may be applied successfully even for $\mathrm{f}>0.5 / 4 /$, and it can easily be verified that they have the correct limiting behavior for $\mathrm{f}=0$ and 1 .

Samples of the Co-B alloy system were prepared by rapid quenching from the melt onto a rotating drum $/ 5 /$. Four probe resistivity measurements were carried out at $\mathrm{T} \leqslant 300 \mathrm{~K}$ using techniques described elswhere $/ 6 /$. It was found that the composition $\mathrm{CoB}_{28}$ (atomic proportions: $28 \% \mathrm{~B}, \mathbf{7 2} \% \mathrm{Co}$ ) produced a completely amorphous ribbon. The weak temperature dependence of resistivity (fig. 1) and the minimum at low temperatures are familiar features for a transition metal-metalloid type of amorphous alloy $/ 6,7 /$. The following linear approximation will be 
used for the temperature coefficient of resistivity $\alpha\left(=p^{-1}\right.$ $\partial \rho / \partial \mathrm{T})$ at $300 \mathrm{~K}: \alpha=\left(1-\rho_{100} / \rho_{300}\right) / 200$. Thus, from figure 1 , for amorphous $\mathrm{CoB}_{28}, \alpha=1.0 \cdot 10^{-4} \mathrm{~K}^{-1}$. A sample of $\mathrm{CoB}_{28}$ was annealed to complete crystallization ( 2 hours at $700 \mathrm{~K}$ ). The ratio of measured room temperature resistivities for the amorphous and crystalline samples was determined to be $\rho_{a} / \rho_{c}=2.4$. A much higher temperature coefficient of resistivity $\left(\alpha=33 \cdot 10^{-4} \mathrm{~K}^{-1}\right)$ vas measured for the crystalline sample (fig. 2) compared to that of the corresponding amorphous sample (fig, 1). This difference in $\alpha$ of the pure phases (amorohous and crystalline) leads to a dependence of $\alpha$ on crystalline fraction $f$ in the case of mixed phases.

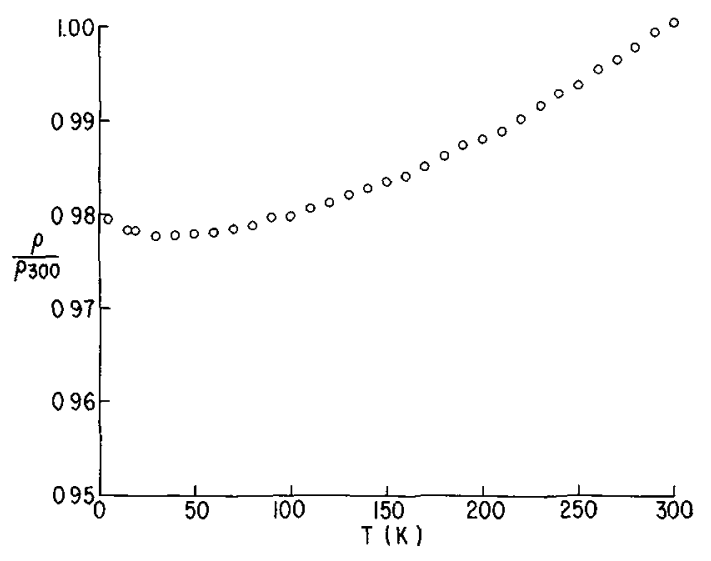

Fig. 1: Fesistivity of amorphous $\mathrm{CoB}_{2 \varepsilon}$ vs. temperature.

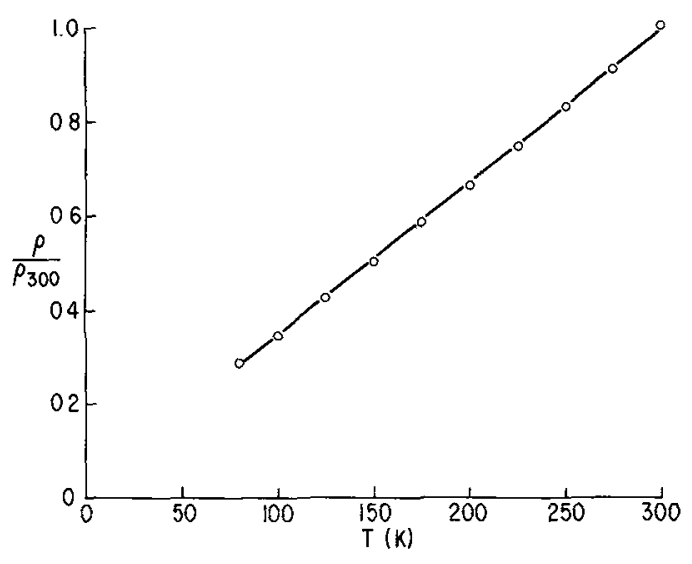

Fig. 2: Resistivity of crystalline $\mathrm{CoB}_{28}$ vs. temperature.
By using the experimental resistivity data discussed above for $\mathrm{CoB}_{28}$ and equations (1) and (2) one can calculate $\rho(f, T)$ (fig. 3 ), assuming that the resistivity of the crystalline phase is not a function of $f$. Calculated values of $\alpha$ are shown as a function of $\mathrm{f}$ in fig. 4. In terms of the percentage of crystals $g(=100 \mathrm{f})$ one arrives at values of $\Delta \alpha / \Delta \mathrm{g}=(3$ or 5$) \cdot 10^{-5} \mathrm{~K}^{-1} \%{ }^{-1}$ for the $2 \mathrm{D}$ or 3D models, respectively. Let $\mathrm{x}$ be the atomic percentage of the variable constituent in a series of amorphous alloys. Comparing the calculated values of $\Delta \alpha / \Delta g$ with values of $\Delta \alpha / \Delta x$ derived from the literature (ranging

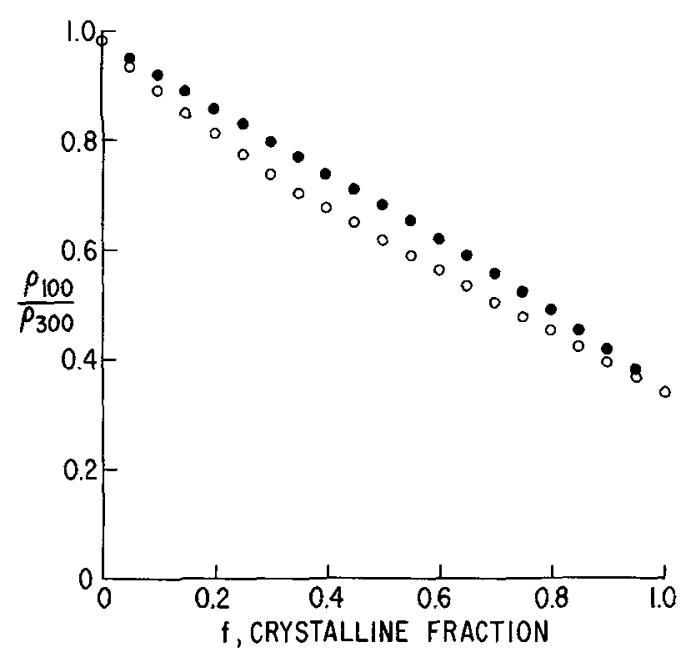

Fig. 3: Resistivity at $100 \mathrm{~K}$ for $\mathrm{CoB}_{28}$ as a function of $\mathrm{f}$, calculated from eqs. (1) and (2) (open circles and filled circles, respectively).

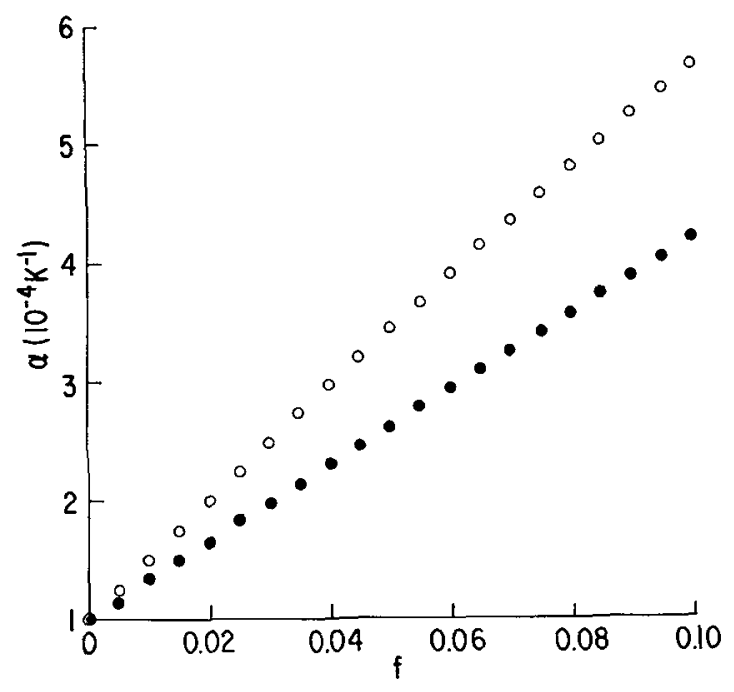

Fig. 4: $\alpha$ at $300 \mathrm{~K}$ vs. $\mathrm{f}$ (calculated for $\mathrm{CoB}_{28}$ ). Open and filled circles using egs. (1) and (2), respectively. 
from 0 to $2 \cdot 10^{-5} \mathrm{~K}^{-1} \%{ }^{-1}$, as seen in Table 1 ), one concludes that they are of the same magnitude. The table also shows for each case the maximum percentage of crystals required to generate the change of $\alpha$ observed over the range of $x$ if $\Delta \alpha / \Delta g=4 \cdot 10^{-5} \mathrm{~K}^{-1} \%^{-1}$ (the value calculated for $\mathrm{CoB}_{28}$ ). On this basis, one concludes that levels of crystallinity of a few percent are important, and in general cannot be neglected in studies of the temperature dependence of resistivity of amorphous alloys.

3. EFFECT OF REMNANT CRYSTALLINITY ON $\mathrm{COB}_{\mathrm{x}}$. Samples of $\mathrm{CoB}_{\mathrm{x}}$ were prepared and microscopic analysis revealed the presence of isolated crystals within an amorphous matrix (figures 5 and 6). Samples used for resistivity studies were examined and found to have the following crystalline fractions $f: x=28, f=0 ; x=22$, $f=0.01 ; x=20, f=0.04 ; x=24, f=0.4$. The measured

TABLE 1

Values of $\left|\frac{\Delta \alpha}{\Delta \mathrm{x}}\right|$ Deduced from the Literature

\begin{tabular}{|c|c|c|c|c|}
\hline $\begin{array}{l}\text { Amorphous } \\
\text { Alloy }\end{array}$ & $\begin{array}{l}\text { Range } \\
\text { of } x(\%)\end{array}$ & $\begin{array}{l}\left|\frac{\Delta \alpha}{\Delta x}\right| \cdot 10^{5} \\
\left(K^{-1}{ }^{-1}\right)\end{array}$ & References & $\begin{array}{l}\text { Maximum g } \\
\text { required }(\%)\end{array}$ \\
\hline$\left(\mathrm{Ni}_{x} \mathrm{Pt}^{\mathrm{P}}\right)_{25}$ & $20-45$ & 0.10 & $/ 8 /$ & 0.6 \\
\hline$\left(\mathrm{Ni} \mathrm{Pd}_{50}\right) \mathrm{P}_{\mathrm{x}}$ & $15-20$ & 1.5 & $/ 9 /$ & 1.9 \\
\hline Ni $P_{x}$ & $15-26$ & 2.1 & $/ 10 /$ & 5.8 \\
\hline $\mathrm{Fe} \mathrm{B} x$ & $15-22$ & 0 & $/ 6 /$ & 0 \\
\hline
\end{tabular}

* These values of the temperature coefficient of resistivity a are valid for $T=300 \quad K_{i}|\Delta \alpha / \Delta x|$ is to be compared
with $\Delta \alpha / \Delta g=4 \cdot 10^{-5} \mathrm{~K}^{-1} \mathscr{W}^{-1}$ calculated (see text) for $\mathrm{CoB}_{28}$ (g $\left.210 \%\right)$

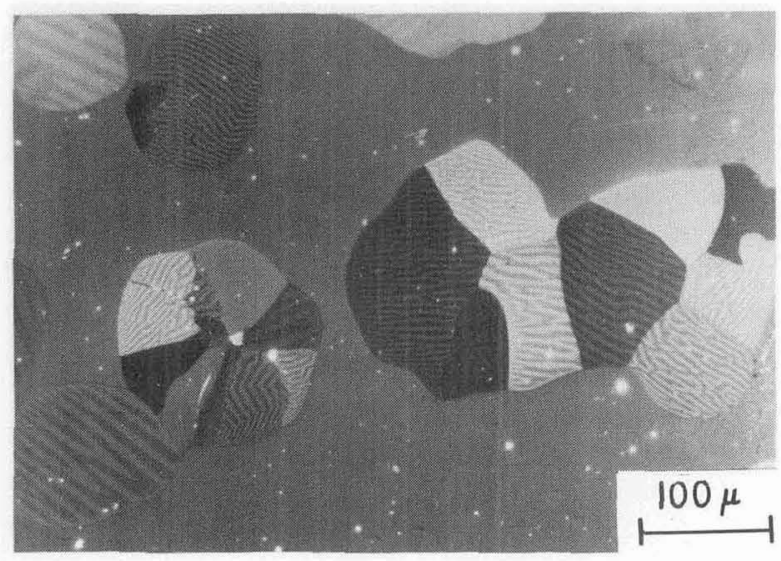

Fig. 5: Optical micrograph showing remnant crystals in a sample of $\mathrm{CoB}_{24}$. The Kerr effect reveals magnetic domains in polarized light. temperature coefficients of resistivity are shown in fig. 7 as a function of $x$ (filled circles), and it is clear that $\mathrm{x}$ is not an ordering parameter. It was found that small amounts of $\mathrm{Si}$ added as a third constituent produced amorphous alloys with no remnant crystals. The data for the series $\mathrm{CoB}_{x} \mathrm{Si}_{2}$ is also shown in figure 7 (open circles), and it can be determined that $\Delta \alpha / \Delta x=2 \cdot 10^{-5} \mathrm{~K}^{-1} \%{ }^{-1}$ is a

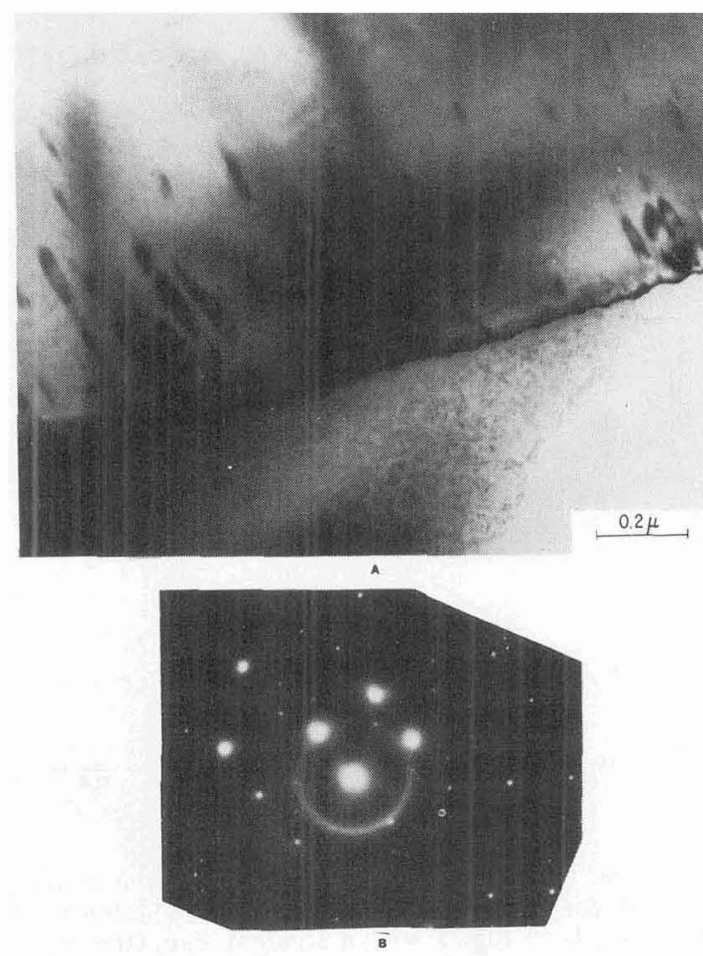

Fig. 6: (A) Electron transmission micrograph of a sample of $\mathrm{CoB}_{25}$ showing a large crystal of $\mathrm{CO}_{3} \mathrm{~B}$ (top) adjacent to amorphous region (bottom), (B) Electron diffraction pattern of the area in (A) which contains both amorphous and crystalline regions.

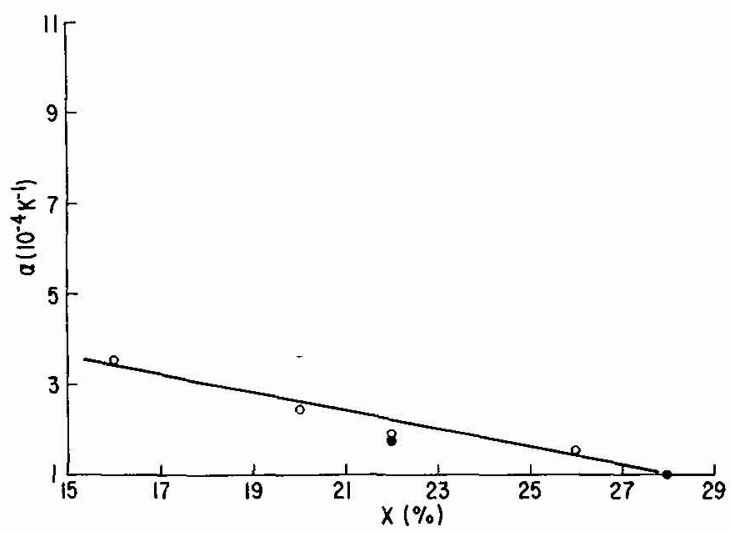

Fig. 7: $\alpha$ vs. $\mathrm{x}$ (open circles: $\mathrm{CoB}_{x} \mathrm{Si}_{2}$; filled circles: $\mathrm{CoB}_{x}$ ). 
good approximation for this series. The addition of only $2 \% \mathrm{Si}$ can be expected to result in minor changes in the number of free electrons. Thus, the data point for the only sample of the $\mathrm{CoB}_{x}$ series with $f=0(x=28)$ falls in line with the $\mathrm{CoB}_{\mathrm{X}} \mathrm{Si}_{2}$ points.

The value of $\Delta \alpha / \Delta x$ for the amorphous $\mathrm{CoB}_{x} \mathrm{Si}_{2}$ series is relatively high (compare with values in Table 1), and thus it is more difficult to recognize the effects of remnant erystallinity on $\alpha$. However, one can do this in an approximate way by comparing the predicted dependence of $\alpha$ on $f$ calculated for $\mathrm{CoB}_{28}$ in section 2 with the observed dependence in the $\mathrm{CoB}_{\mathrm{X}}$ series. This comparison is made in figure 8; the agreement is reasonable.

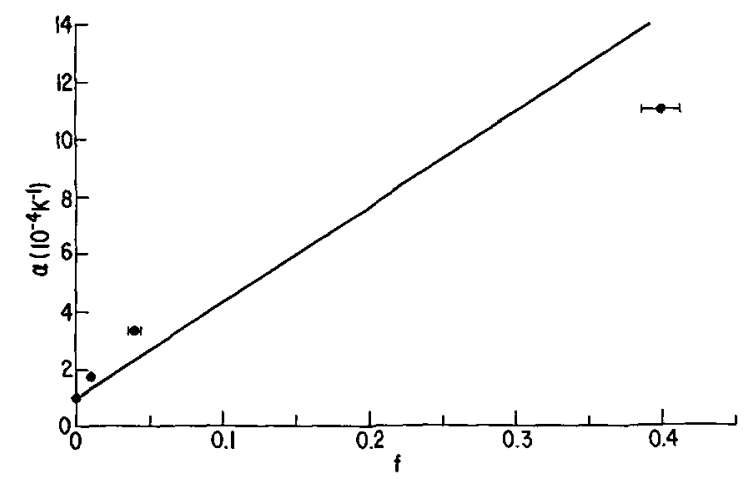

Fig. 8: $\alpha$ vs. $f$ for $\mathrm{CoB}$. The straight line is the behavior calculated for $\mathrm{CoB}_{28}$ it corresponds to joining the extreme points in Fig. 3 with a straight line, (the crystal sizes were observed to be of the order of the ribbon thickness, so that neither the purely $2 \mathrm{D}$ or $3 \mathrm{D}$ models seem entirely appropriate).

\section{CONCLUSION.- According to the extended Ziman} theory of resistivity, changes in $\alpha$ are interpreted in terms of shifts of the Fermi wavevector $k_{F}$ with respect to the structure factor of the amorphous alloy, and the observation of negative temperature coefficients has provided significant support for this interpretation (e.g., see/11/). The origin of the resistivity minimum at low temperatures has also aroused considerable interest (e.g., see/ $/ 7 /$. It is clear from the present analysis that changes of $\alpha$ with $f$ can be a significant contributor to the total change in $\alpha$, and therefore special care must be taken to minimize or eliminate the effects of remnant crystallinity. In particular, negative temperature coefficients can be transformed to positive ones by the presence of remnant crystals.

Acknowledgements.- C. P. Bean pointed out references $2-4$, and figure 5 was obtained from J. D. Livingston. W. R. Giard, W. E. Rollins, and L. G. Turner provided experimental assistance. The transmission electron microscopy was done by E. F. Koch.

\section{References}

11/ Walter, J.L., J. Non-Cryst. Solids, in press (1980); also available as GE Report No. 79CRD235.

/2/ Maxwell, J.C., A Treatise on Electricity and Magnetism, v. 1, 3rd ed., Oxford, (1904) 441.

/3/ Rayleigh, L., Phil. Mag. 34 (1892) 481.

14/ Cole, K.S., Li, C.-L., and Bak, A.F., Exp. Neur. 24 (1969) 459 .

15/ Walter, J.L., in Rapidly Quenched Metals III, v. 1, ed. B. Cantor, The Metals Society, London (1978) 30 .

16/ Mogro-Campero, A., and Walter, J.L., Phys. Rev. B 20, (1979) 5030 .

/7/ Cochrane, R.W., J. Phys. 39 (1978) C6 - 1540.

/8/ Sinha, A.K., Phys, Rev. B 1 (1970) 4541.

/9/ Tsuei, C.C., in Amorphous Magnetism II, ed. R.A. Levy and R. Hasegawa, Plenum Press, New York (1977) 181.

/10/ Cote, P.J., Solid State Commun. 18 (1976) 1311.

/11/ Güntherodt, H.-J., and Künzi, H. U., in Metallic Glasses, ed. J. J. Gilman and H. J. Leamy, American Society for Metals, Metals Park, Ohio (1978) 247. 